Health Promotion Policy in Europe 


\section{Soziologie und Sozialpolitik}

Herausgegeben von Bernhard Badura, Christian von Ferber, Franz-Xaver Kaufmann, Eckart Pankoke, Theo Thiemeyer

Band 12

R. Oldenbourg Verlag München 2000 
Alfred Rütten, Günther Lüschen, Thomas von Lengerke, Thomas Abel, Lasse Kannas, Josep A. Rodríguez Diaz, Jan Vinck \& Jouke van der Zee

\section{Health Promotion Policy in Europe}

Rationality, Impact, and Evaluation

R. Oldenbourg Verlag München 2000 
Die Deutsche Bibliothek - CIP-Einheitsaufnahme

Health promotion policy in Europe : rationality, impact, and evaluation / Alfred Rütten ... - München : Oldenbourg, 2000

(Soziologie und Sozialpolitik ; Bd. 12)

ISBN 3-486-56475-7

(C) 1999 Oldenbourg Wissenschaftsverlag GmbH, München Rosenheimer Straße 145, D - 81671 München

Internet: http://www.oldenbourg-verlag.de

Das Werk einschließlich aller Abbildungen ist urheberrechtlich geschützt. Jede Verwertung außerhalb der Grenzen des Urheberrechtsgesetzes ist ohne Zustimmung des Verlages unzulässig und strafbar. Dies gilt insbesondere für Vervielfältigungen, Übersetzungen, Mikroverfilmungen und die Einspeicherung und Bearbeitung in elektronischen Systemen.

Gedruckt auf säurefreiem, alterungsbeständigem Papier (chlorfrei gebleicht). Gesamtherstellung: WB-Druck, Rieden am Forggensee 